\title{
Review on Development and Performance Evaluation of Maize Sheller
}

\author{
Merga Workesa Dula \\ Bako Agricultural Engineering Research Center, \\ Oromia Agricultural Research Institute
}

\begin{abstract}
In the present paper, an effort has been taken to perform a literature review on the development and performance evaluation of maize shelling machine. Maize shelling or simply maize threshing is the most important aspect of post-harvest operation of maize. It involves detaching of the maize grain from its cobs. Now days, few motorized, tractor/ power tiller operated machines have come into the market. Some hand operated maize shellers have been developed but they shell only one cob at a time and have limitations to use it continuously for a longer period of time. Therefore, it was the aim of this investigation to review the design of existing maize shelling machine and the performance evaluation parameters, and see the design parameters which are highly influencing operational performance of maize sheller.
\end{abstract}

Key words: Sheller, maize, moisture contents, performance evaluation

\section{INTRODUCTION}

Maize (Zea mays) is an important cereals crop which belongs to a grass family (Gramineae) producing small edible seeds (as cited by, Aremu et.al, 2015). Maize, also called corn, is believed to have originated in central Mexico 7000 years ago from a wild grass, and Native Americans transformed maize into a better source of food. It is the world's best adapted crop, growing between latitudes $58^{\circ} \mathrm{N}$ and $40^{\circ} \mathrm{S}$ of the equator. It is a versatile grain crop and commonly known as corn in America. The natural endowment of high rainfall, high light intensities, and favorable temperature in the cultivation of maize make it to be one of the world's most versatile seed crops (as cited by, Aremu et.al, 2015). Maize contains approximately $72 \%$ starch, $10 \%$ protein, and $4 \%$ fat, supplying an energy density of $365 \mathrm{Kcal} / 100 \mathrm{~g}$ and is grown throughout the world, with the United States, China and Brazil being the top three maize-producing countries in the world, producing approximately 563 of the 717 million metric tons/year (Peter and Juan ,2014).

After wheat and rice, maize is the most important cereal grain in the world, providing nutrients for humans and animals and serving as a basic raw material for the production of starch, oil and protein, alcoholic beverages, food sweeteners and, more recently, fuel. Maize accounts for $15-20 \%$ of the total daily calories in the diets of people in more than 20 developing countries mainly Latin America and Africa (as cite by, Dauda, 2015). It is used in various forms to alleviate hunger, and such forms include pap or ogi, maize flour (Oriaku, et.al. 2014).
Approximately $88 \%$ of maize produced in Ethiopia is consumed as food, both as green and dry grain. Maize for industrial use has also supported growing demand. Very little maize is currently used as feed but this too is changing in order to support a rapidly growing urbanization and poultry industry. Unlike its neighbor, Kenya, which imports a significant share for its consumption needs, Ethiopia has increasingly attained selfsufficiency in maize production since early this decade and even exports some quantities to neighboring countries (e.g., Sudan and Djibouti) in years of surplus production (Tsedeke et.al, 2015).

Abebe and Hundie (2006) report reaffirms that maize continues to be a significant contributor to the economic and social development of Ethiopia. As the crop with the largest smallholder coverage at 8 million holders (compared to 5.8 million for teff and 4.2 million for wheat), maize is critical to smallholder livelihoods in Ethiopia. In addition, maize is the staple crop with the greatest production at 4.2 million tons in 2007/08, compared to teff at 3.0 million tons and sorghum at 2.7 million tons(Kindie et.al, 2010).

The major steps involved in the processing of maize are harvesting, drying, dehusking, shelling, storing, and milling. For the rural farmers to maximize profit from their maize, appropriate technology that suites their needs must be used. The processing of agricultural products like maize into quality forms not only prolongs the useful life of these products, but increases the net profit farmers make from mechanization technologies of such products. One of the most important processing operations done to bring out the quality of maize is shelling or threshing of maize. For maize one of its postharvest challenges is shelling. Kaul and Egbo, 1985 reported that maize harvested are traditionally shelled by hand or by beating sacks stuffed with maize cobs with wooden flails. These traditional methods of shelling maize are time wasting, hazardous and associated with lots of drudgery (Oriaku et.al,2014).

Shelling of the dried cobs by majority of farmers in Ethiopia is carried out by repeated beating of the cobs with a club while held inside Sacks, open barrels or spreading it over plastered ground floor in the house or outdoor (Ashwin and Shaik, Nyongesa and Patil et.al, 2014). This methods cause damage to the kernels and are time consuming involving drudgery. Other traditional maize 
shelling technique is rubbing the maize cobs against one another by hand or by direct removal of kernels pressing it between thumb and hand palm. Not only this but also, most mechanical shellers were designed for multi-grain threshing or shelling, which causes great damage to the maize seeds besides breaking the cob to pieces. So that to alleviate the drudgery process of maize shelling traditional by beating the cobs by sticks and rubbing hands and as well as to assure the quality of the product, employing mechanical sheller like maize shelling machine whose parts are well designed with minimum damage to the crop is required.

\section{LITERATURE REVIEW}

\subsection{Maize Shelling}

Maize shelling is a postharvest operation by which the removal of maize seeds from the cob is done. This operation can be carried out in the field or at the storage environment (Nwakire, et.al, 2011). Maize shelling therefore is an important step towards the processing of maize to its various finished products like flour. The different methods of maize shelling can be categorized based on various mechanization technology used. Shelling is best attained when the moisture content is as low as $13 \%$ (Ashrae, 1998). Shelling is an indispensable process which is undertaken to maximize space and promote the easy handling of grains.

\subsection{Methods of Maize Shelling}

\subsubsection{Hand Shelling}

The easiest traditional system for shelling maize is to press the thumbs on the grains in order to detach them from the ears. Another simple and common shelling method is to rub two ears of maize against each other. These methods require a lot of labour. It is calculated that a worker can hand shell only a few kilograms per an hour. Shelling of maize can be more efficiently accomplished by striking a bag full of ears or heads with a stick. Maize and sunflowers can also be shelled by rubbing the ears or heads on a rough surface. Small tools, often made by local artisans, are sometimes used to hand shell maize. With these tools, a worker can shell 8 to $15 \mathrm{~kg}$ of maize an hour (Patil, et.al, 2014 and John, et.al, 1989)

\subsubsection{Threshing With Animals}

If draught animals are available and there are large quantities of maize, threshing can be done by driving the animals (harnessed, in that case, to threshing devices) over and animals were used in threshing on the field by marching on the maize(Onwualu et.al, 2011).

\subsubsection{Maize-Shelling With Hand-Operated Machines}

Manual shellers, which are relatively common and sometimes made by local artisans, permit easier and faster shelling of ears of maize. These come in several models, some of them equipped to take a motor; they are generally driven by a handle or a pedal. Use of manual shellers generally requires only one worker. With yields of from 14 to $100 \mathrm{~kg} / \mathrm{min}$, they are well-adapted to the needs of smallscale production. Hand operated rotary maize shellers have been found suitable for small and marginal farmers for shelling maize, especially for seed purposes, as damage grains are lower in comparison to power operated maize shellers (Ashwin and Shaik, 2014).

\subsubsection{Power Operated Sheller}

Engine powered technology involves the use of mechanical assistance in shelling the maize. To facilitate speedy shelling of maize in order to reduce postharvest deterioration, mechanical shellers are recommended, because hand shelling methods cannot support commercialized shelling ( Nwakaire,et.al, 2011).

Nowadays many small maize shellers, equipped with a rotating cylinder of the peg or bar types are available on the market. Their output ranges between 500 and 2000kg per hour, and they may be driven from a tractor power take off or have their own engine; power requirements vary between 5 and $15 \mathrm{hp}$ according to the equipment involved (Nyongesa, 2009).

\subsection{Design Requirement and Consideration}

The main aim of design is to obtain maximum performance from the machine. It was discovered that the factors influencing maize shelling efficiency can be grouped under machine parameters and crop properties. There are also engineering design factors that affect the design of mechanical shellers. These factors are the design of the power transmission shaft, key, selection of the prime mover, type of pulley, appropriate chain drive design and selection of appropriate bearings support (Danfulani, 2009).

\subsubsection{Physical and Mechanical Properties of Maize} The crop parameters which are of importance include the moisture content, the biometric properties such as size of the grain, grain cob ratio, grain bulk density, sphericity, angle of repose, terminal velocity, one thousand grain mass and porosity. For processing of maize seeds in general and threshing in particular, it is necessary to determine some physical properties, which in most cases, are dependent on the moisture content. These properties include dimensions (size, shape), bulk density, porosity, coefficient of static friction, volume, weight, specific gravity, density, porosity, surface area, angle of repose and angle of internal friction; have been pointed out their practical utility in machine and structural design processes and control engineering (as cited by, Dauda, 2015).

Coskun et al. (2006) and determined the physical properties of sweet corn seed as a function of moisture content in the range of 11.54 to $19.74 \%$ (d. b.). The average length, width and thickness were $10.56 \mathrm{~mm}, 7.91 \mathrm{~mm}$ and $3.45 \mathrm{~mm}$, at moisture content of $11.54 \%$ (d. b.), respectively. For the moisture ranged from $11.54 \%$ to $19.74 \%$ (d. b.), studies on rewetted sweet corn seed showed that the thousand seed mass increased from 131.2 to 145.5 $\mathrm{g}$, the projected area from 59.72 to $75.57 \mathrm{~mm}^{2}$, the spheiricty from 0.615 to 0.635 , the true density from 
1133.8 to $1225.5 \mathrm{~kg} \mathrm{~m}^{-3}$, the porosity from $57.48 \%$ to $61.30 \%$ and the terminal velocity from 5.56 to $5.79 \mathrm{~ms}^{-1}$. The bulk density decreased from 482.1 to $474.3 \mathrm{~kg} \mathrm{~m}^{-3}$ with an increase in the moisture content range of 11.54$19.74 \%$ (d. b.). The static coefficient of friction of sweet corn seed increased the linearly against surfaces of four structural materials; rubber (0.402-0.494), aluminum (0.321-0.441), stainless steel (0.267-0.401) and galvanized iron $(0.364-0.477)$ as the moisture content increased from $11.54 \%$ to $19.74 \%$ (d. b.).

El-Fawal et al. (2009) developed a database of physical and engineering properties of grains of some main and popular feed, industrial crops. The studied crops; fennel flower, rice (Giza 101), rice (Giza 177), broad bean, corn (hyb. 310), corn (hyb. 352), wheat (Giza 9) and wheat (Giza 168) and their selection were based on their recent coverage area and the expected future expansion of each variety. Various physical properties including grain dimensions (length, width and thickness), the weight of thousand grain, bulk density, percent of sphericity, projected area and the mechanical properties including angle of repose and coefficient of friction, in addition to the aerodynamic properties including terminal velocity, drag coefficient and Reynold's number, were determined at storage moisture content $7-12 \%$ (w. b.). The obtained data showed that it was the use of stainless steel or galvanized iron in manufacturing of seed hopper used in planting machines, silos and storage containers with side inclination of $40^{\circ}$ allow easy sliding of grains. The physical properties of seed play an important role to select the proper separating and cleaning equipment and the main dimensions were considered in selecting and designing the suitable size of the screen perforations.

Tarighi et al. (2011) were studied the physical and mechanical properties of corn seeds as a function of moisture content in the range of 5.15 to $22 \%$ (d. b.). The average length, width, thickness and arithmetic diameter were increased by $6,2.2,1.66$ and $3.3 \%$, with increasing moisture content, respectively. In the moisture range from 5.15 to $22 \%$ (d. b.), the results showed that, the thousand seed mass increased from 267.7 to $305.8 \mathrm{~g}$, the porosity from 31.41 to $45.98 \%$, the static angle of repose from 42 to $57^{\circ}$ and the coefficient of friction on compressed plastic, plywood and galvanized iron sheet surfaces were increased from 0.36 to $0.67,0.36$ to 0.6 and 0.38 to 0.57 , respectively. The bulk density decreased from 679.1 to 632 $\mathrm{kg} \mathrm{m}^{-3}$ and true density increased from 999.33 to 1170.49 $\mathrm{kg} \mathrm{m}^{-3}$.

Montellano et al. (2012) determined the mechanical properties of maize grains and olives required for use in discrete element method (DEM) simulations. The DEM was a numerical technique specifically designed for the simulation of the mechanical behavior of granular materials. This work reports the experimental determination of values for several of the microscopic properties like, particle density, modulus of elasticity, particle wall coefficient of restitution, particle-particle coefficient of restitution and the particle wall coefficient of friction-of maize grains and olives, required for use in DEM simulations.

\subsubsection{Development of shelling unit}

Sakun (1963) used wire loop cylinder in place of rasp-bar and found that use of wire loop cylinder resulted in better threshing performance than using rasp-bar cylinder in threshing of corns.

Hamid et al. (1980) developed a low damage corn shelling machine based on the principle of axial flow to reduce the shelling force and to increase the shelling efficiency. The sheller consisted of three inclined rollers rotating in the same direction but at different speeds at an angle of $20^{\circ}$ with the vertical. The ears were fed axially between the rollers through a gap of $33 \mathrm{~mm}$. The test was carried out at the moisture contents of $24 \%, 22 \%, 20 \%, 18 \%$ and $16 \%$ at a speed of $900 \mathrm{rpm}, 1000 \mathrm{rpm}, 1100 \mathrm{rpm}$ and $1200 \mathrm{rpm}$, respectively. The shelling capacity and shelling efficiency found to be $330 \mathrm{~kg}$ per hour and $97.4 \%$, respectively at $1200 \mathrm{rpm}$ and moisture content was below 20\%. It was found that the breakage was low in hand and high in combine shelling compared to the roller sheller.

Liao et al. (1994) developed machine vision systems for detection of corn kernel breakage and have shown promising results. Most machine vision systems were designed to classify corn kernels into two or more damage categories, such as no damage, minor damage and severe damage. One problem with this approach was that mechanical damage occurs on a continuous scale from hairline cracks and tiny spots of pericarp missing to complete breakage, which makes separation of damaged kernels difficult. It would be useful to have machine vision systems that determine the damage level on a continuous scale that was proportional to the damage severity.

Kumar et al. (2002) studied a cost effective, improved design for safe operation of sheller based on ergonomic principles. The study was done in villages of Sonipat district of Haryana State and Baraut district of Uttar Pardesh. They interviewed all the injured victims with serious cuts or amputations taking treatment in nearby hospitals. Found that $4 \%$ of victims were under 16 years, $82 \%$ in $16-45$ years and $14 \%$ over 45 years. The right hand was involved in $80 \%$ cases; left hand was involved in $15 \%$ and other body parts 5\%. Thirty-five cases involved amputations of the right hand fingers, right hand, right forearm, left hand fingers and left hand. They analyzed machine parts associated with injuries revealed that the threshing drum and the feeding system were involved in 52 cases, belt and pulley in 6 cases and rest by any other machine part.

Danfulani (2009) carried out an investigation on design of a maize shelling machine. He used a rotating shaft with threshing tooth on the surface to provide the shelling forces required. The machine designed to shell $5000 \mathrm{~kg}$ of maize 
per day. The prime mover selected as a diesel engine with a capacity of 5 hp which could be easily be operated by rural dwellers. The design was done with readily available materials coupled with minimum cost without affecting the quality of its output.

Tastra (2009) reported about the development of a new power sheller that could reduce grain damage and broken corn cobs. The Senap-II sheller was operated by 6.5 to $8.5 \mathrm{hp}$ diesel engine with highest shelling of capacity $4.82 \mathrm{t}$ $\mathrm{hr}^{-1}$ which was lower than the existing local sheller. The basic principle of this new machine was the reduction of the normal stress during the shelling process by developing a concave system that could vibrate without causing great impact on the maize grain.

Yadav et al. (2010) conducted the analytical studies on strength parameters of Indian farm workers and its implication in equipment design. The strength parameters of 105 agricultural workers ( 75 male and 30 female) were measured on "strength measurement setup" comprising load cell with digital indicator. The average push strength for male and female workers (with both hands in standing posture) was found to be 248.2 and $171.0 \mathrm{~N}$, respectively whereas the pull strength in standing posture was 232.3 and $141.7 \mathrm{~N}$, respectively. These strength parameters were found to play a significant role in design of manually operated push-pull type equipment. The right hand push and pull strength for male and female agricultural workers were within the range of 49.7 to $96.5 \mathrm{~N}$ which prominently assist in the design of joystick, gear shift lever and handle lever. The mean value of maximum right leg strength in sitting posture for male and female workers were 394.2 and $280.5 \mathrm{~N}$, respectively which were found useful in the design of clutch pedal, brake pedal, accelerator pedal, pedal operated thresher and other foot operated controls. Average torque strength of both hands in standing posture for male and female workers were found to be 209.93 and $117.72 \mathrm{~N}$ $\mathrm{m}$, respectively which can be used in the design of manually operated equipment like chaff cutter, sugarcane crusher, slicer, threshers etc.

Singh et al. (2011) reviewed the status of maize sheller in India. The output in terms of dehusking shelling maize cob was reported that $30 \mathrm{~kg}$ per hectare with $8.3 \%$ grain damage in traditional system (dehusking by hand and shelling by beating wooden sticks). The power operated maize dehusker sheller may be suitable for strong group of farmers (medium and large farmers) while in the country, about $80.3 \%$ of farmers of marginal and small group operates $36 \%$ of the area. The hand operated maize dehusker cum sheller was suitable for farm women workers.

\subsubsection{Performance Evaluation of sheller}

Vas and Harrison (1969) stated that the cylinder speed was primarily influences the damage caused to the seed than that of concave clearance although the concave clearance was an important parameter as well. Impact force was the primary threshing action for detachment of grain from the ear head. In all types of sheller the most crucial adjustment for control of impact was the cylinder tip speed.

Singh and Pathak (1973) studied impact phenomena in threshing affected by different parameters. They have stated that the peripheral velocity of impact member and the elasticity of its material have a direct influence on the threshing percentage. Further, they have stated that shape of impact member has measurable influence on threshing phenomena.

Sandhar and Panwar (1974) studied on machine crop variables influencing shelling of the maize. The study concluded that the shelling efficiency increased with increase in cylinder speed and reduction in concave clearance. The square section members shelling more than the round and rasp bars and shelling decreased with grain moisture. The grain damage was higher at higher cylinder speed and at lower value of the concave clearance.

Mahmoud and Buchele (1975) found that, ear head axis parallel to cylinder axis orientation suffered the least damage at all moisture content levels tested, followed by ears fed randomly to the cylinder. The highest damage was suffered by ears fed with their axis perpendicular to the cylinder. The minimum damage for all orientations was at 20 to $22 \%$ moisture content. They found that the corn kernel damage increased with an increase in moisture content and cylinder velocity.

Chowdhury and Buchele (1976) found that kernel moisture content and cylinder speed were highly significant in analysis of variance for damaged corn kernel percentages. Total damage increased from $26 \%$ to $41 \%$ as cylinder velocity increased from 450 to $650 \mathrm{rpm}$ (12.87 and $18.73 \mathrm{~m}$ $\left.\mathrm{s}^{-1}\right)$. Minimum total damage was sustained at $23 \%$ moisture content (w. b.). They found that the mechanical damage by the laboratory sheller ranged between 26.3 and $42 \%$ for cylinder velocities of 12.87 to $18.73 \mathrm{~m} / \mathrm{s}$.

Chhabra and Singh (1977) reported that the extent of seed damage was directly proportional to the impact energy and inversely proportional to the seed moisture content.

Kravchenko and Kuceev (1979) determined that adhesion between a grain and the maize cob depends on the grain moisture content and its location on the ear. At the ear base kernel attachment is the strongest and at the top it is the weakest. As grains dry, their adhesion to the cob increases. In order to detach grains from the cob some force should be applied longitudinal or perpendicular to the ear axis. When threshing the ears approximately $66 \%$ of power is used to overcome the friction forces between the grains and only $34 \%$ of power is used for the ear deformation. The main influences on maize shelling are the gap between drum rasp bars and the concave and the drum peripheral velocity. They were found that the optimum speed of the shelling drum rasp bar was $11 \mathrm{~m} / \mathrm{s}$. This was about 2.5 times less 
than the movement speed of the rasp bars when the grain crops were being shelled.

Wrubleski and Reed (1980) conducted a study to investigate the performance of a modified cylinder and concave. The cylinder and concave modification consisted of shimming the cylinder bars to a $0.75 \mathrm{~mm}$ radial tolerance, building up the concave bars so that they were at least $8 \mathrm{~mm}$ above the rods and machining the concave to give it a diameter $3 \mathrm{~mm}$ larger than the cylinder diameter.

Vindizhev and Blaev (1983) obtained the data that shows maize grain damage occurred when the drum rasp bars operated at a rate of $7 \mathrm{~ms}^{-1}$ and their impact direction coincided with the longitudinal axis of a grain. When the impact direction is at an angle with the grain longitudinal axis, the damage appears at rasp bar speeds of $15 \mathrm{~ms}^{-1}$. During the harvesting of maize the number of ears fed to the threshing drum varies considerably.

Gupta et al. (1985) conducted studies on the performance of tractor operated combine for maize shelling. The machine was tested on maize with and without husk. The performance of the machine was evaluated in terms capacity, cylinder loss and grain breakage. It was concluded that the combine gave satisfactory results for husked maize at a speed of $500 \mathrm{rpm}$, concave clearance of $25 \mathrm{~mm}$ and feed rate of 3 tonnes per hour. Whereas for the unhusked maize the satisfactory results were obtained at a cylinder speed of $575 \mathrm{rpm}$ and cylinder concave clearance of $25 \mathrm{~mm}$ and the capacity of the machine was found to be 2- 2.5 tonnes per hour. The damage in case of husked and dehusked maize was found to be 2.72 (maximum) and $2 \%$, respectively.

Norris and Wall (1986) were investigated that corn kernel damage may be decreased and concave separation efficiency increased by changes some of the concave design parameters. The experimental results shows that corn kernel damage can be decreased by at least $24 \%$ and concave separation efficiency can be increased by at least $38 \%$; however, these improvements were accompanied by a significant increase in the quantity of foreign (non-grain) material passing through the concave.

Kustermann (1987) states that during the first impact of the rasp bar the greatest number of grain are shelled. The degree of grain shelling depends on the ear orientation with respect to the drum shaft position. When the ear axis is parallel to the drum shaft grain shelling losses are 2.3 times lower than in case of shelling when the ears fed perpendicular to the drum shaft. Most researches on maize shelling have evaluated the ear shelling process with respect to grain damage and grain losses during shelling. However, the reasons for grain damage or loss during the shelling do not often evaluate the movement of ears in the threshing apparatus.
Nalbant (1990) studied the percentage of corn grain damage caused by the cylinder and concave before and after the grains were shelled from the cob. The effect of grain moisture content and cylinder velocity on grain damage was also investigated. Cylinder velocity of $7 \mathrm{~ms}^{-1}$ and $11 \mathrm{~ms}^{-1}$ were used in the shellers. Corn varieties were shelled with grain moisture content of $15 \%, 20 \%$ and $25 \%$. Damaged grain percentage increased with an increase in moisture content and cylinder velocity. Mechanical damage was also affected by the concave clearance, physical and morphological properties of corn ear and feeding rate.

Tastra et al. (1990) tested that, three types of local maize shellers were tested at three levels of grain moisture content and cylinder speed. The effective shelling capacity increased with an increase of the cylinder speed but decreased with an increase of the moisture content of maize. Mechanically damaged maize increased with increasing cylinder speed and with moisture content of maize. The total drying cost decreased with an increase in moisture content.

Ajav and Igbeka (1995) tested the performance of corn sheller using an international standard codes to study the general qualities and design of sheller. The results show that the shelling efficiency of the sheller varies with moisture content, speed of the shelling unit and feed rate. The machine had a shelling efficiency of 98, 95 and $94 \%$ when shelling corn with a moisture content of 11, 20 and $25 \%$, respectively. The sheller had a cleaning efficiency of 93, 87 and $85 \%$ when shelling corn with moisture content of 11,20 and $25 \%$, respectively, with a shelling unit speed of $400 \mathrm{rpm}$ and fan unit speed of $750 \mathrm{rpm}$. The sheller had a capacity of $260 \mathrm{~kg} \mathrm{hr}^{-1}$. The performance tests proved that the sheller performed better at shelling unit speed of 450 rpm with minimum losses and high efficiency.

Gite and Singh (1997) found that, more practical if the equipment was developed for women workers as in most of the cases the equipment (dehusker-sheller) suitable for women workers suits to the men workers because ergonomical characteristics like, aerobic capacity, muscular strength of women workers, anthropometrical dimensions etc. were less than men workers. Thus, a hand operated maize dehusker cum sheller has been designed, developed and fabricated for dehusking and shelling undehusked cobs.

Mudgal et al. (1998) have reported about the development of hand operated maize dehusker, pedal operated maize dehusker, pedal operated maize dehusker cum sheller, power operated maize dehusker and power operated maize dehusker-sheller at MPUAT, Udaipur. Dehusker unit was made using a pair of rubber and spirally welded mild steel rod on steel rollers. Some serrated blades were used lengthwise to facilitate the dehusking. A combined unit for dehusking and shelling in one cylinder was tried by using half of the cylinder length with rasp bars and the other with 
rubber strips in octagonal cylinder to act as dehusker and sheller, respectively.

Kunjara et al. (1998) conducted an experiment on a sheller with rasp bar sheller and peg-tooth sheller. The both sheller are highly efficient (99\%), shelling unit loss and grain breakage was less than $1.5 \%$. Nevertheless, a limitation of the rasp bar sheller was that in the long run the residual broken corn remained on the concave, thus reducing the amount of grains passing the concave. The power consumption and shelling drum speed of the peg-teeth sheller were double of that of the rasp bar sheller. Both corn shellers were not corn husker sheller.

Gasparetto et al., (1989) was investigated the crop movement in the threshing apparatus and found that the shelled dry ear in the concave move 4 times slower than the shelled drum rasp bars and that the shelled grains move in several directions in the threshing apparatus. The shelling of ears with moisture content greater than $30 \%$ has not been fully investigated because grain moisture should be less than $30 \%$ when maize ears are harvested for storage. Rotary shelling units in which the crop is fed axially or tangentially into the rotor are becoming more popular.

Changrua (1999) developed an axial flow shelling unit of corn husker sheller. Efficiency was rather high, but shelling capacity was not good. Corn ears also remained a short time in the shelling unit resulting in less shelling than it should be.

Akubuo (2002) reported that, manual shelling of maize was time consuming and tedious operation. The few existing mechanized shellers on Nigerian farms were imported and out of reach of the rural peasant farmers that were characterized by small holdings and low income. The power requirement of such shellers was high and hence, the prime mover was very expensive. The shelling capacity was not significantly influenced by harvest date or maize variety. Generally, the performance of the maize sheller was not influenced by maize the variety; therefore, the maize sheller can comfortably be used to shell local maize varieties.

Olaoye (2002) reported that some crop parameters and machine variables were known to influence the performance of threshers. Each or combination of these parameters had influencing effects on the threshability and grain damage. He noted that the influence of both threshability and grain damage translate to measurable grain losses if not properly managed.

Wacker (2005) investigated that the threshing of ears with medium moisture content concentrates on grain damage. $\mathrm{He}$ also determined that the least maize grain damage (11\%) occurred when the moisture content was $28 \%$ wet basis. On threshing of maize grains on $41 \%$ moisture wet basis, grain damage increased to $33 \%$.Wacker (1987) also stated that grain damage from an axial threshing machine is less than that of a tangential machine.

Victor et al. (2006) conducted an evaluation of the performance of a tractor powered maize sheller and shelling with tractor wheels. The performance of the maize shellers and the traditional shelling techniques were evaluated in terms of shelling efficiency, grain output and grain damage. The test result revealed that shelling of maize with tractor wheels incurred the highest percentage of grain damage. A maximum grain output of about $80 \mathrm{~kg}$ per hectare was obtained with the tractor powered maize sheller compared to $30.90 \mathrm{~kg}$ per hectare by shelling with tractor wheels and $13.19 \mathrm{~kg}$ per hectare with the traditional shelling techniques. Shelling with tractor wheels had the lowest shelling efficiency of about $73.76 \%$ when compared with the other shelling methods.

Nkakini et al. (2007) reported that manually powered sheller can provide a continuous flow at a speed of $60 \mathrm{rpm}$. A shelling effectiveness of $67 \%$ was achieved, with a low kernel-breakage factor of 0.09 and a throughput of $6.82 \mathrm{~kg}$ $\mathrm{hr}^{-1}$. This sheller uses abrasion between a rotating shellingdisc and stationary concave compartments to achieve the stripping. This design was preferred, because of its rapid operation, low human energy expenditure, low breakage factor for the kernels as well as relatively little dust being emitted during shelling; hence leading to a relativelyhealthier local atmosphere for the operator. Its wider use was therefore recommended.

Sachin (2008) conducted short duration test for maize sheller and his data revealed that the machine was stable and strong. Its speed of operation was $60 \mathrm{rpm}$. The shelling capacity of the machine was $100.25 \mathrm{~kg}$ per hectare with shelling efficiency of $99.95 \%$ and cleaning efficiency of $99.37 \%$. The breakage percentage was 0.406 which was well within the prescribed limit for such machines. The labour requirement was reduced by $89.60 \%$. Singh (2008) developed a $5.5 \mathrm{~kW}$ motor operated whole crop maize thresher using spike tooth cylinder at MPUAT, Udaipur. This machine performed dehusking-shelling the maize cob and simultaneously and stalk was converted to chaff.

Pathak (2008) reported about a shelling machine consisting of shelling unit, reduction unit (worm and worm gear type) and single-phase $1 \mathrm{hp}$ electric motor. The power from electric motor was transmitted to the worm shaft and then from gear shaft to the shelling unit shaft. The developed power operated maize sheller was tested in laboratory as well as operations at load for short durations. The analysis of data collected during the short duration tests revealed that the machine was stable and strong and its speed of operation of $60 \mathrm{rpm}$ was quite satisfactory. The shelling capacity of the machine was $100.25 \mathrm{~kg}$ per hectare with shelling efficiency of $99.95 \%$.

Petkevichius et al., (2008) investigated that the most important quality indices for maize ears shelling were grain 
loss, damage, concave separation, and the degree of the ear length reduction. The threshing process depends on the maize variety characteristics, the design and structure of the shelling apparatus, and its adjustment.

Hussain et al. (2009) reported that the horizontal maize cob sheller, very useful to the farmers of hilly region, was evaluated for three varieties, like local collection Kashmir, north decota pop-1 and composite almora to study the different parameters like shelling capacity, labour requirement, shelling efficiency, grain recovery and grain damage. The results were compared with traditional methods of maize cob shelling (beating by sticks and hand rubbing). When the shelling capacity and labour requirement were concerned, the horizontal maize cob sheller was significantly superior over both traditional methods. Regarding shelling efficiency, the difference between mechanical maize cob shelling and shelling by hand rubbing was found to be non-significant.

Singh et al. (2010) conducted an experiment to minimize the drudgery of farm women in maize shelling. A tubular maize sheller was introduced and tested on farm women. The results revealed that the shelling efficiency of tubular maize sheller was $26 \mathrm{~kg} \mathrm{hr}^{-1}$ as compared to hand shelling by which they only could shell $13 \mathrm{~kg} \mathrm{hr}^{-1}$. About $43 \%$ saving in cost of workers per unit of output in comparison to the hand shelling.

Tiwari et al. (2010) studied the effect of operating speed and cob size on performance of a

Abba and Atiku (2010) studied the effect of moisture content on maize shelling speed using a manually operated hand sheller in Mubi, Adamawa State. Twenty unshelled maize cob samples (A-J) were used for analysis. The result indicated that sample $\mathrm{J}$, after sixty nine hours $\left(69^{\text {th }}\right)$ oven drying recorded the lowest moisture content $15.10 \%$ (w. b.) and the fastest shelling speed $0.75 \mathrm{rpm}$ compared to sample. A 24 hour drying time which had the highest moisture content $28.99 \%$ (w. b.) and lowest shelling speed $0.96 \mathrm{rpm}$. It was observed that sample ' $\mathrm{J}$ ' with the shortest shelling duration had the smallest grains weight $84.2 \mathrm{~g}$, while sample 'A' recorded larger grain weight of $162.9 \mathrm{~g}$ due to differing moisture content of the maize grains. It was recommended that maize cobs be dried properly to enable easier and faster shelling operation with less fatigue and minimum grain damage.

Naveenkumar, (2011) modified power operated machine with pegs cylinder, mild steel rod concave and was evaluated at different cylinder speeds of $250 \mathrm{rpm}, 300 \mathrm{rpm}$ and $350 \mathrm{rpm}$ at moisture contents of $12 \%, 13 \%$ and $14 \%$ for same sample size yields and shelling efficiency were more at $350 \mathrm{rpm}$. The Author reported that, the speed increased performance of threshing was more but obviously broken grains more at increased speed but this combination gave more output. Considering the performance of each combination, the total duration of shelling, labor and energy requirement, it was observed that when maize having $13 \%$ moisture content were fed to the shelling having cylinder peed at $350 \mathrm{rpm}$ gave best performance of shelling.

Naveenkumar and Rajshekarappa ( 2012) evaluated the performance of improved power operated sheller having steel rod made concave and radial feeding mechanism; the result obtained shows that shelling efficiency and capacity of the sheller were $98.51 \%$ and $402.01 \mathrm{~kg} / \mathrm{hr}$., respectively. By considering all factors such as percentage of whole kernels, efficiency, unshelled kernels and capacity, it was found that shelling process of maize having $13 \%$ moisture content, fed at cylinder speed of $350 \mathrm{rpm}$ gave better results but there was considerable damage as compared to slow speed of operation.

Shaik, (2014) developed hand operated maize sheller radial type feeding mechanism and spike/peg cylinder with concave made of round bar or mild steel rod and the clearance between concave and cylinder was adjustable but normally it is around 2 to $3 \mathrm{~cm}$. It was reported that for hand operated maize sheller at a moisture content of $12 \%$ w.b., and at a feed rate of $130 \mathrm{~kg} / \mathrm{hr}$ the shelling efficiency, unshelled percentage and visible damage is found to be $99.56 \%, 0.44 \%$ and $1.07 \%$, respectively.

Oriaku et.al, (2014) designed and evaluated performance, the concave was made of perforate barrel and pegs cylinder, the results show that the machine has an average feed rate of $123.6 \mathrm{~kg} / \mathrm{hr}$ while average threshing efficiency was obtained as $78.93 \%$, while the average separation efficiency was $56.06 \%$. These values were show an improvement on the values obtained for human labour as reported by Nwakire et al, (2011) where human mechanical efficiency was determined to be $45 \%$ at the biomaterial test weight of $20 \mathrm{~kg}$ with actually shelled grain weight of 15.8 $\mathrm{kg}$. They also reported that human throughput capacity was $26.67 \mathrm{~kg} / \mathrm{hr}$ and actual grain handling capacity of 21.1 $\mathrm{kg} / \mathrm{hr}$ at a shelling time of 45 minutes or $0.75 \mathrm{hr}$. this shows clearly that the designed machine would perform satisfactorily and can process about 0.11 tonne/hr of maize. The design can be modified in order to find ways to improve the separation efficiency. The effect of cylinder and concave bar variations on threshing of corn was investigated by Pickard (1955). He reported that rasp-type cylinder bar appeared to be superior to the angle the cylinder bar in terms of shelling efficiency and kernel damage. Covering the cylinder or concave bars with rubber had little effect on shelling efficiency or kernel damage.

Idowu, ( 2015) developed and tested the performance of the motorized maize sheller with peg cylinder and round bar concave and was achieved that the shelling efficiency, cleaning efficiency, grain recovery efficiency, sheller performance index, total grain losses and output capacity are $87.08 \%, 95.89 \%, 95.48 \%, 91.55 \%, 2.96 \%$ and $623.99 \mathrm{~kg} / \mathrm{hr}$ respectively at $13 \%$ moisture contents of maize and $886 \mathrm{rpm}$ shelling speed. 
Sachin, (2016) designed and developed dehusker cum sheller with peg type and perforated concave, for optimizing operational parameters of the prototype for efficient performance, the performance evaluation of the dehusker cum sheller were carried out with major influencing factors like; feed rate $(400,500$ and $600 \mathrm{~kg} / \mathrm{hr})$, cylinder peripheral speed $(6.2,6.6,7.2$ and $7.6 \mathrm{~m} / \mathrm{s})$ and concave clearance $(20,25,30$ and $35 \mathrm{~mm})$ on four different maize varieties. The result indicated that mean value of terminal velocity of maize grains and husk were $15.12 \mathrm{~m} / \mathrm{s}$ and $1.2 \mathrm{~m} / \mathrm{s}$, respectively. The mean values of frictional properties like, angle of repose of grains and coefficient of friction of grains with mild steel sheet was observed to be 0.44. The maximum dehusking efficiency was of $99.71 \%$ in $400 \mathrm{~kg} / \mathrm{hr}$ feed rate whereas lowest dehusking efficiency of $84.65 \%$ was recorded in $800 \mathrm{~kg} / \mathrm{hr}$ feed rate. The dehusking efficiency increases with increase in cylinder peripheral speed and decreases with increase in feed rate and concave clearance among the different treatments. The maximum shelling efficiency of $99.68 \%$ was observed with $400 \mathrm{~kg} / \mathrm{hr}$ feed rate for the $30 \mathrm{~mm}$ of concave clearance and $7.6 \mathrm{~m} / \mathrm{s}$ cylinder peripheral speed, where as it was minimum of $91.02 \%$ for $800 \mathrm{~kg} / \mathrm{hr}$ feed rate at $35 \mathrm{~mm}$ of concave clearance and $6.2 \mathrm{~m} / \mathrm{s}$ cylinder peripheral speed. The shelling efficiency increases with an increase in cylinder peripheral speed and decrease in concave clearance and feed rate. The maximum cleaning efficiency of $99.40 \%$ was found for $400 \mathrm{~kg} / \mathrm{hr}$ feed rate at $20 \mathrm{~mm}$ concave clearance up to $7.1 \mathrm{~m} / \mathrm{s}$ cylinder peripheral speed, whereas the lowest value of cleaning efficiency of $91.06 \%$ was observed for $800 \mathrm{~kg} / \mathrm{hr}$ feed rate at $35 \mathrm{~mm}$ concave clearance and $6.2 \mathrm{~m} / \mathrm{s}$ cylinder speed combination. The blower loss percentage found to be increases steadily with an increase in cylinder peripheral speed up to $7.1 \mathrm{~m} / \mathrm{s}$ later on it increases abruptly. The blower loss percentage was observed to be decreased with increase in feed rate and concave clearance. The broken grain percentage and seedcoat damage were found to be increased with an increase in cylinder peripheral speed and decrease in concave clearance and feed rate. Among these three factor cylinder speed had predominant effect on the broken grain percentage and seed-coat damage. The lowest total loss was found at the feed rate of $600 \mathrm{~kg} / \mathrm{hr}$ operating with cylinder peripheral speed of $7.1 \mathrm{~m} / \mathrm{s}$ with $25 \mathrm{~mm}$ concave clearance.

Waree et.al., (2016) conducted experiment and reported that, Peg tooth clearance (PC), concave rod clearance (CR), and concave clearance (CC) significantly affected shelling unit loss and power consumption, but not grain breakage. Increase in peg tooth clearance (PC) and concave clearance (CC) or decrease in concave rod clearance (CR) resulted in an increase of total loss from the shelling unit. But increase in peg tooth clearance (PC), concave rod clearance (CR), and concave clearance (CC) resulted in reducing power consumption for shelling. The linear model was the optimal model of the design factors affecting shelling unit loss (TL), with $2.76+0.03 \mathrm{PC}-0.20 \mathrm{CR}+0.10 \mathrm{CC}$ with $\mathrm{R}^{2}$ of 0.92 . The linear model was the optimal model of design factors affecting power consumption (P), with 1987.99 4.76PC - 2.81CR - 17.98CC with $\mathrm{R}^{2}$ of 0.72 .

Waree et.al., (2016) conducted study using axial flow shelling unit consisted of spike toothed cylinder. They have investigated the range of factors affecting losses and the power consumption of an axial flow corn shelling unit with moisture content $(\mathrm{mc})$, feed rate $(\mathrm{Fr})$ and rotor speed (Rs). The result indicated that the rotor speed had significant impact on shelling unit losses, moisture content and rotor speed had a significant impact on the grain breakage and moisture content, feed rate and rotor speed had significant on power consumption.

\section{SUMMARY}

The report of many Authors indicated that maize shows increased demand of production from time to time throughout different country of the world since it is versatile source of nutrients for humans and animals as well as serving as raw materials for industries. Beside to high production demand quality postharvest production generally calls for well-designed shelling machines. Shelling is the major postharvest operation in which grains are separated from ear heads by traditional method, hand operated mechanical sheller and power operated shellers. According to the investigation of research findings, the traditional way of maize shelling was caused a lot of damage to the maize grain and involving the drudgery too. To alleviate the problem different mechanical shellers have been designed and developed. The operational performances of these shellers have been optimized by determining the crop and machine parameters thoroughly.

The physical and mechanical properties of the crop have the combined effect on the cylinder performance. Various physical properties including grain dimensions(length, width and thickness), bulk density, true density, percent of sphericity, projected area, porosity, moisture content and mechanical properties including angle of repose and coefficient of friction, in addition to the aerodynamic properties including terminal velocity, drag coefficient and Reynold's number, were have a practical utility in machine design, for these reasons the physical properties of agricultural products are studied by considering them individually because of their irregular shape and variability in size.

Additionally pertinent machine parameters affecting design, performance and evaluation of shellers include the cylinder type, feed rate, the concave length, the concave clearance, concave hole size, concave rod clearance, fan (air) speed, sieve oscillation frequency and the cylinder peripheral velocity (drum speed).

Finally the combination of the machine and crop parameters exhaustively determined by different researchers to evaluate the performance of the sheller like shelling efficiency, grain loss, grain damage, output Capacity, cleaning efficiency, power requirement and threshing recovery. 
Therefore kernel moisture content is a major factor that has a great influence on kernel damage ( Mahmoud and Buchele (1975), Chowdhury and Buchele (1976), Hamid et al. (1980, Ajav and Igbeka (1995), Abba and Atiku (2010), Naveenkumar, (2011), Naveenkumar and Rajshekarappa ( 2012), Shaik, (2014) and Oriaku et.al, (2014),). These researchers reported that mechanical kernel damage increased rapidly with increasing moisture content over approximately $20 \%$, however, corn shelled at moisture contents considerably below $20 \%$ moisture also suffered high levels of damage.

Mahmoud and Buchele (1975), Chowdhury and Buchele (1976), Kravchenko and Kuceev (1979), Nalbant (1990), stated the cylinder peripheral velocity of maize sheller with higher cleaning and shelling efficiency is ranged between 7 to $11 \mathrm{~m} / \mathrm{s}$.

Joshi (1981), Gupta et al. (1985), Shaik, (2014) and Sachin, (2016), stated that the severity of the shelling action is controlled by the cylinder speed and the cylinder to concave clearance. Clearance at the front of the concave is approximately 20 to $30 \mathrm{~mm}$. Kustermann (1987), Hamid et al. (1980), Wacker (2005), concluded that axial feeding in which the axis of the cob is parallel to the axis of the cylinder cause less damage to the corn kernel than feed at an angle.

\section{REFERENCES}

[1] Abate Tsedeke, Bekele Shiferaw, Abebe Menkir, Dagne Wegary, and Yilma Kebede. 2015. 'Factors That Transformed Maize Productivity in Ethiopia', avaliable at <https://doi.org/10.1007/s12571-015-0488-z> accessed June 20, 2017.

[2] Ajav, E. A., and J. C. Igbeka, 1995, Performance evaluation of a maize sheller. Nigerian Defence Academy Kaduna, 7622

[3] Akubuo, C. O., 2002, Performance evaluation of a local maize sheller. Biosystems Engg., 83(1): 77-83.

[4] Anonymous, 1986, Consolidated final report 1975-1986 of operational research project on post-harvest technology (Coimbatore center): pp. 72-78.

[5] Aremu, D.O, I.O. Adewumi and J.A. Ijadunola. 2015. Journal of Biology, Agriculture and Healthcare, Department of Agricultural Engineering, Federal College of Agriculture, Ibadan, Nigeria, 5(5):2224-3208

[6] Ashwin, K., and S.H. Begum. 2014. Design, development and performance evaluation of a hand operated maize sheller, International Journal of Agricultural Engineering, 7(1):194-197

[7] Begum and H. Shaik. 2014. 'Design, Development and Performance Evaluation of a Hand Operated Maize Sheller', 7: 194-97

[8] Chhabra, S. D. and K. N. Singh, 1977, Effect of cylinder speed and peg spacing of axial flow thresher on wheat threshing. $J$. Agril. Engg., 14:141-144.

[9] Chowdhury, M. H. and W. F. Buchele, 1978, The nature of corn kernels Damage inflected in the shelling crescent of grain combines. Trans. of the ASAE, 21(4): 610-614.

[10] Coskun, B., M.Y. Ibrahim and C. Ozarslan, 2006, Physical properties of sweet corn seed (Zea mays saccharata Sturt.). $J$. Food Engg., 74: 523-528.

[11] Danfulani A. M., 2009, Design and construction of a maize sheller. Nigerian Defence Academy Kaduna, 7622.

[12] Dauda, D. N., 2015, Development Of Modeling Shelling Parameters And Optimization Of The Performance Of A Stationary Iar Maize Dehusker Sheller, Department Of Agricultural ngineering Ahmadu Bello University Zaria.

[13] 'Design , Fabrication and Performance Evaluation of a Motorized Maize Shelling Machine Design, Fabrication and Performance
Evaluation of a Motorized', 2015

[14] Gite, L. P., and G. Singh, 1997, Ergonomics in agricultural and allied activities in India. Technical Bull., No. CIAE/97/70.Centra Institute of Agril. Engg., Bhopal.

[15] Gole, S. V. and R. Shahu, 2009, Ergonomically designed thresher. Agril. Mechanization in Asia, Africa and Latin America, 40(2): 73-75

[16] Gupta, P. K., S. Singh, and V. K. Sharma, 1985, Performance studies on tractor operated combine for maize threshing. Agril. Engg. Today, 9(4): 40-42.

[17] Hamid, F., Al. Jalil, M. Stephen, H. Mofazzal, and Chowdhury, 1980, Laboratory studies of a low damage corn shelling machine. Trans. of the ASAE, 10(1): 278-283.

[18] Hassan, A. B, M. S. Abolarin, and O. A. Olugboji, 2009, Design and construction of maize threshing machine. Assumption Univ. $J$. Techno.,12(3):199- 206

[19] Hussain, S. Z., H. R. Naik, A. H. Rather and J. Khan, 2009 Comparative evaluation of horizontal maize cob sheller with traditional methods of maize shelling. Res. on Crops 10: 168-170.

[20] Kumar, A., D. Mohan, R. Patel and M. Varghese, 2002, Development of grain threshers based on ergonomic design criteria. Applied Ergonomics, 33: 503-508

[21] Kindie Getnet, Shahidur Rashid and Solomon Lemma, 2010 , 'Maize Value Chain Potential in Ethiopia', International Food policy Research Institutes 1-42

[22] Liao, K., M. R. Paulsen and J. F. Reid, 1994, Real-time detection of color and surface defects of corn kernels using machine vision. J. Agril. Engg. Res., 59(4):263-271.

[23] Mahmoud, A. R., and W. F. Buchele, 1975, Distribution of shelled corn throughput and mechanical damage in a combine cylinder. Trans. ASAE, 18(2): 448-452.

[24] Montellano, C., J. M. González Fuentes, E. Ayuga-Téllez and F. Ayuga, 2012, Determination of the mechanical properties of maize grains and olives required for use in DEM simulations. $J$ Food Engg., 111: 553-562.

[25] Mudgal, V. D., N. K. Jain, J. S. Bordia and P. Seth, 1998 , Research Digest (1992-97) Udaipur Centre. AICRP on PHT, CTAE, Udaipur, pp. 17- 18.

[26] Nalbant M., 1990, Mechanical damage on corn kernel in shelling corn ear. Agril. Mechanization in Asia, Africa, Latin America, 21(2): 37-40.

[27] Naveenkumar, D.B., 2011, 'Modification and Evaluation of Power Operated Maize ( Zea Mays L .) Sheller. Department Of Agricultural Engineering, University of Agricultural Sciences, Bangalore.

[28] Naveenkumar, D.B., and K. S. Rajshekarappa, 2012, 'Performance Evaluation of a Power Operated Maize Sheller', 5:172-77

[29] Nkakini, S. O., M. J. Aytamuno, G. P. D. Maeba, S. O. T. Ogaj and S. D. Probert, 2007, manually powered continuous-flow sheller. Applied Energy, 84: 1175-1186.

[30] Norris, E.R., and G.L. Wall. 1986. Effect of concave design factors oncylinder- concave performance in corn.Can. Agric. Eng. 28: 97-99.

[31] Nwakaire, J.N., B.O. Ugwuishiwu, and C.J. Ohagwu, 2011 'Design, Construction and Performance Analysis of a Maize Thresher for Rural', 30

[32] Olaoye, J. O., 2002, Performance modeling of a multipurpose crop threshing machine for Assessment of grain loss. Being an aspect of the research findings for the 1997, Senate Research Grant, University of Ilorin, Nigeria.

[33] Onwualu, A.P., C.O. Akubuo, and I.E. Ahaneku. 2006. Fundamental of Engineering for Agriculture. mmaculate Publications Limited Enugu Nigeria.

[34] Oriaku, E.C., C.N. Agulanna, H.U. Nwannewuihe, and M.C. Onwukwe. 2014.'Open Access Design and Performance Evaluation of a Corn De-Cobbing and Separating Machine'127 36

[35] Ranum, Peter, and J. Pablo .2014. 'Global Maize Production Utilization, and Consumption' 1312:105-12

[36] Sachin, C., 2016, Development and Performance Evaluation Of Modified Maize Dehusker Cum Sheller, Department Of Farm Machinery \&Power Engineering Vaugh School Of Agriculture Engineering and Technology, India.

[37] Sachin P., 2008, Design, development and evaluation of a powe 
operated maize sheller (Spiked Disk Type). Int. J. Agric. Sci., 4:215-219.

[38] Sakun, V.A., 1963, Testing and threshing with logarithmic shape of teeth. Agric. Hort. Engg. Abst.,16(2): 54-64.

[39] Sandhar, N. S., and J. S. Panwar, 1975, Force and energy requirements for detaching grains from cobs. J. Agril. Engg., 10 (5 \& 6): 29-32.

[40] Patil, S.B., A. D. Chendake, M. A. Patil, S. G. Pawar, R. V. Salunkhe and S. S. Burkul. 2014. "Development and performance evaluation of pedal operated maize sheller". International Journal of Advanced Research, 2(9):561-567,

[41] John, S., F. Iris and R. Weil, "Labor saving home and village technology for food processing and preparation". Food Technology Branch, Office of International Cooperation and Development, U.S. Department of Agriculture, pp.52, 1989.

[42] Singh, A., U. S. Gautam, P. Surendra and S. Anju, 2010, Ergonomic evaluation of farm women during maize shelling. Indian Res. J. of Exten. Educ.,10(3): 41-44.

[43] Singh, S. P., P. Singh and S. Singh, 2011, Status of maize threshing in India. Agril. Mechanization in Asia, Africa and Latin America,42(3): 21-28.

[44] Singh, S. and B. S. Pathak, 1973, Impact phenomena in threshing affected by different parameters, J. Agril. Engg.,10(2): 54-64.

[45] Srison,W., S. Chuan-udom, and K. Saengprachatanarug, 2016, 'Design Factors Affecting Losses and Power Consumption of an Axial Flow Corn Shelling Unit',38: 591-98

[46] Tarighi, J., A. Mahmoudi and N. Alavi, 2011, Some mechanical and physical properties of corn seed (Var. DCC 370). African J. Agril. Res., 6(16): 3691-3699.

[47] Tastra, I. K., 2009, Designing and testing of improved maize sheller. Agril. $\quad$ Mechanization in Asia, Africa and Latin America, 40(1): 12-17.

[48] Tastra, I. K., E. Ginting and R. Merx, 1990, Determination of the optimum moisture content for shelling maize using local sheller. Internal Report MARIF ATA- 272/NRC, pp. 33.

[49] Vas, F. M. and H. D. Harrison .1969.The effect of selected mechanical threshing parameters on kernel damage and threshability of Wheat. Canadian Agril. Engg., 11(2): 83-87.

[50] Victor, I. O., Ndirika and R. J. Buys, 2006, Intermediate agricultural processing technologies for cereal crops in South Africa. Agril. Mechanization in Asia, Africa and Latin America, 37(2): 24-28.

[51] Wacker, P. (2005). Bechaedigung von Maiskoernern bei der Getreideernte. Damage of Maize Grains by Harvesting. Landtechnik, 60(2), 84-85.

[52] Yadav, R., P. Sahastrarashmi, N. C. Patel and L. P. Gite. 2010, Analytical study of strength parameters of Indian farm workers and its implication in equipment design. Agri. Engg. Int.: CIGR E-J., 12(2): 49-54. 